\title{
Contando histórias com realidade aumentada: estratégia para promover a fluência da leitura infantil
}

\author{
Telling stories with augmented reality: a strategy to increase fluency in children's reading
}

\author{
Angela Chuvas Naschold \\ Sheila Balen \\ André Campos \\ Selan Rodrigues dos Santos \\ Universidade Federal do Rio Grande do Norte - Natal - Rio Grande do Norte - Brasil \\ Michele Soltoski \\ Universidade Federal Fluminense - Niterói - Rio de Janeiro - Brasil \\ Joseli Brazorotto \\ Antonio Pereira \\ Universidade Federal do Rio Grande do Norte - Natal - Rio Grande do Norte - Brasil
}

$\diamond$

\begin{abstract}
Resumo: O objetivo deste trabalho é discutir o papel das tecnologias digitais no incentivo à leitura infantil. A compreensão textual de estudantes brasileiros é muito precária, e são necessárias medidas eficazes para melhorar esse quadro. Uma estratégia é fomentar a leitura desde os primeiros anos de escola, na esperança de que melhorias na fluência, na construção de vocabulário e no desenvolvimento de atração pela narrativa textual possam contribuir para a criação de uma sociedade leitora. Neste trabalho, discutimos e apresentamos uma proposta de utilização de uma tecnologia digital em particular, a realidade aumentada, que cria uma nova perspectiva de interação com o livro como objeto físico, para melhorar a fluência da leitura e auxiliar a melhorar os índices de compreensão leitora dos estudantes brasileiros.
\end{abstract}

Palavras-chave: Compreensão leitora; Fluência leitora; Realidade aumentada

\begin{abstract}
This paper aims to discuss the role of digital technologies in stimulating children's reading. Brazilian students' reading comprehension is very poor, and effective actions are necessary to improve this situation. One strategy is to stimulate reading habits since the early grades, hoping that improvements in fluency, vocabulary building and increased interest in narratives may contribute to the creation of a society of readers. In this paper, we discuss and present a proposal for the utilization of augmented reality, a digital technology that has brought about a new perspective for interacting with books as physical objects, in order to improve Brazilian students' reading fluency and their performance in reading comprehension tests.
\end{abstract}

Keywords: Reading comprehension; Reading fluency; Augmented reality

\section{Apresentação do problema}

Os indicadores de desempenho da população brasileira em leitura são preocupantes. De acordo com a pesquisa "Retratos da Leitura no Brasil" (FAILA, 2012), o brasileiro lê em média apenas quatro livros por ano, incluídos livros didáticos e literatura religiosa. Esse índice é inferior ao obtido na pesquisa anterior e demonstra que o livro no Brasil está perdendo a competição para o seu maior rival, a televisão.
Esses índices são incompatíveis com as aspirações geopolíticas do Brasil e são refletidos em avaliações internacionais, como o teste PISA (Programme for International Student Assessment) da OECD (Organização para o Desenvolvimento dos Estados Americanos), que avalia o desempenho de estudantes de 15 anos de idade de vários países do mundo em matemática, ciências e leitura. No último PISA (OECD, 2012) o desempenho dos estudantes brasileiros em leitura baixou dois pontos em relação a 2009, ficando em um modestíssimo 
55ํำ lugar entre os 65 países participantes. Esses resultados são piores que o de países da América Latina com economias muito menores que a nossa como o Chile e o Uruguai. Entre os países de colonização espanhola nas Américas (OECD, 2012), por exemplo, o Brasil ficou

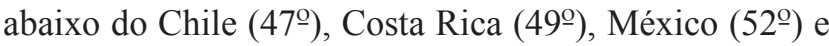
Uruguai (54으.

De acordo com esses resultados, quase metade $(49,2 \%)$ dos alunos brasileiros está no nível 1 em leitura, dos seis possíveis na avaliação de PISA. Esses dados implicam que quase metade da população de jovens brasileiros de 15 anos não é capaz de deduzir informações básicas de um texto, de estabelecer relações entre as diferentes partes e de compreender o sentido do texto lido. Além disso, remetem à dificuldade de construir uma cultura leitora robusta no Brasil. Estabelece-se um ciclo vicioso, e os jovens que não têm o hábito da leitura dificilmente vão incutir esse gosto em seus filhos. Esse panorama coloca nos ombros da escola a responsabilidade maior na formação de leitores fluentes (NASCHOLD et al, 2015). Infelizmente, apesar desse quadro negativo, dentre as 20 metas listadas no atual Plano Nacional de Educação, há referência à leitura somente na quinta meta, cujo foco se dirige ao ensino inicial da leitura, não existindo no plano nenhuma meta explicitamente voltada para o desenvolvimento de uma sociedade leitora, isto é, para o alcance dos níveis mais elevados de compreensão leitora pelo conjunto da sua população.

O desenvolvimento da competência leitora é uma tarefa extremamente complexa. O leitor iniciante deve coordenar vários processos cognitivos para ler com precisão e fluência (HUDSON et al., 2008). O relatório do Painel Nacional de Leitura (National Reading Panel) dos Estados Unidos da América, National Institute of Child Health and Human Development (NICHD, 2000), destacou cinco componentes essenciais que devem ser considerados para formar leitores proficientes: 1. alfabeto (ensino de consciência fonêmica e fonética); 2. fluência; 3. compreensão (ensino de vocabulário e de texto); 4. leitura (realização de leituras silenciosa e em voz alta, entre outras); 5. tecnologias da informação a serviço do ensino da leitura. O relatório salienta que, em todas essas atividades é necessário que os professores dominem os conceitos subjacentes a esses conhecimentos na execução do ensino, o propósito de ensinar às crianças consiste em aplicar essas habilidades com precisão e fluência em suas atividades de leitura e escrita de forma integrada. Ainda, segundo o relatório, esses componentes são os que permitem o reconhecimento das palavras, a manutenção da informação lida na memória e a consequente atribuição de significado ao texto pela apropriação da compreensão de seu sentido, decorrentes de modificações estruturais que ocorrem no cérebro do leitor. Além do benefício direto no aprendizado, o desenvolvimento da leitura e da escrita também beneficia a cognição em geral, numa dinâmica recíproca (STANOVICH, 1993).

Quando a criança inicia o processo de alfabetização formal, ela já demonstra uma competência considerável de comunicação linguística, empregando estratégias de linguagem altamente complexas. Essa competência é essencial para o desenvolvimento da leitura e da escrita. A compreensão, nesse contexto, configura-se como a etapa mais avançada da alfabetização. A decodificação é uma das primeiras etapas, e sem ela é impossível formar leitores competentes que possam adquirir o hábito da leitura. Para olhos acostumados a ler, decodificar pode parecer evidente e simples, porém, para uma criança iniciante na leitura, as letras ligadas a um nome e, sobretudo, a sons são algo bastante complexo que exige grande capacidade de análise cognitiva pelo fato de a escrita não corresponder exatamente à linguagem falada. Todas essas nuances da relação entre fala, leitura e escrita constituem-se na base de registro das palavras na memória permanente para seu uso imediato pela automação da leitura e consequente fluência. No entanto, é somente com a prática que, aos poucos, a fluência se instalará na memória permanente.

A fluência é a capacidade de ler o texto com a rapidez e a precisão necessárias para garantir o entendimento (WOLF; KATZIR-COHEN, 2001). Normalmente, a fluência é negligenciada na sala de aula, embora seja uma característica importante da leitura hábil (ALLINGTON, 1983; NICHD, 2000). Os principais determinantes da fluência na leitura são o automatismo e a precisão no reconhecimento das palavras e a prosódia (KUHN et al., 2010). Vários estudos têm mostrado uma forte ligação entre a fluência e a compreensão leitora: estudantes com pouca fluência também pouco compreendem o texto (para revisão, ver HIRSH, 2003). O motivo é que a falta de automatismo, associado coma baixa fluência, desvia recursos cognitivos que são necessários para a compreensão do texto (KLAUDA; GUTHRIE, 2008).

Em termos cognitivos, o fator limitante mais importante para a automação na leitura é a capacidade da memória operacional ou de trabalho (NEVO; BREZNITZ, 2011). A memória operacional é usada quando precisamos manter uma informação na mente por um breve período, suficiente para realizar uma tarefa com a mesma. A habilidade de manter informação verbal na memória operacional é essencial para a leitura (CAIN et al., 2004). A maioria dos processos envolvidos na compreensão leitora, tal como a integração semântica e sintática das palavras nas frases e a criação de uma representação coerente do texto, depende da capacidade de memória operacional. A memória operacional serve como um repositório temporário das informações lidas recentemente no texto, permitindo a coerência textual, e 
também daquelas recuperadas da memória declarativa, facilitando sua integração com as ideias do texto, sua integração e coerência (COOKE et al., 1998).

A memória operacional possui três componentes, de acordo com o modelo proposto por Baddeley (BADDELEY; HITCH, 1974; BADDELEY, 2003): o componente executivo central, que tem capacidade limitada de atenção, o componente fonológico e o componente visuoespacial, sendo que ambos têm capacidade de armazenamento limitada e estão subordinados ao executivo central. Recentemente, foi adicionado outro componente, o buffer episódico, que também possui capacidade limitada e armazena informações relacionadas com a memória episódica (BADDELEY, 2003).

Além dos limites intrínsecos na capacidade, a utilização da memória operacional está associada com uma carga cognitiva decorrente do esforço consciente e da atenção sustentada. Por isso, é importante para a fluência leitora automatizar ao máximo os processos de decodificação do texto, para liberar a capacidade de memória operacional para o entendimento do texto. Essa é uma das razões que justificam a máxima de que "bons leitores se fazem lendo", sendo esse um dos mais eficazes meios para o alcance da automação da leitura e consequente compreensão do que é lido.

\section{A leitura e o cérebro humano}

A consolidação da escrita alfabética, iniciada pelos gregos por volta do século VIII a.C. catalisou transformações cognitivas responsáveis por mudanças radicais na cultura humana. $O$ período que vai do século VIII ao II a.C. foi chamado de "Era Axial", devido à simultaneidade extraordinária no surgimento das principais religiões e filosofias que formam a base da cultura moderna (JASPERS, 1954). Existem várias hipóteses para explicar essas mudanças mentais, entre elas, uma desoneração da memória, permitindo à mente vagar com liberdade criar narrativas próprias, desapegadas da "internalização de vozes externas" (ONG, 1982).

Uma análise filológica de termos associados com a introspecção demonstrou que existe uma tendência crescente na incidência de termos introspectivos na literatura ocidental, iniciando com o velho testamento e continuando de maneira acelerada em textos subsequentes até o século XX (DIUK et al., 2012). Esses resultados são sugestivos de mudanças acentuadas na mente, possivelmente estimuladas pela leitura dos textos escritos. De maneira interessante, foram comprovadas mudanças estruturais e funcionais no cérebro humano durante o processo de alfabetização (DEHAENE; COHEN, 2011).
A leitura é uma invenção cultural, ou seja, não é uma adaptação cognitiva engendrada por mecanismos darwinianos de seleção natural e registrada no código genético. O desenvolvimento da leitura depende de um processo de "reciclagem neuronal" em áreas corticais de processamento de informação visual e linguagem em seres humanos (DEHAENE; COHEN, 2011). Por exemplo, à medida que o indivíduo é alfabetizado, áreas visuais localizadas no sulco occípito-temporal esquerdo seletivas para o processamento de estímulos visuais complexos, como objetos e faces, passam a ser estimuladas também por símbolos da escrita (DEHAENE; COHEN, 2011). A lesão seletiva dessa área, chamada de área da forma visual das palavras (AFVP), provoca alexia pura (PFLUGSHAUPT et al., 2009), um déficit seletivo no reconhecimento de palavras que, ao ser diagnosticado numa manhã de outubro de 1887 , inaugura a história das neurociências cognitivas da leitura. $\mathrm{Na}$ ocasião, um homem culto e acostumado à leitura diária instalase para ler um livro, quando percebe que não pode ler uma palavra sequer. Sua impossibilidade, causada por um acidente vascular cerebral, é acompanhada pelo neurologista Joseph-Jules Déjerine, que denominará de "cegueira verbal pura" o que hoje recebe o nome de alexia pura (DEHAENE, 2007). Pouco mais de quatro anos depois, o paciente sofre um segundo acidente vascular cerebral, e Déjerine (1892) acompanha o desfecho do caso desse paciente, realizando minucioso exame de seu cérebro, ocasião em que verifica que, na região occipital esquerda, há uma lesão que deve ter causado a alexia pura do paciente quando em vida. Essa região, que corresponde exatamente ao que hoje denominamos de área da forma visual das palavras (AFVP), Déjerine denominou de "centro visual das letras".

$\mathrm{Na}$ alexia pura, a linguagem oral, a escrita e o reconhecimento visual e tátil de objetos, rostos, desenhos e mesmo de números permanece vastamente preservado, bem como o reconhecimento gestual ou tátil das palavras. É possível ao portador de alexia pura "ler" as letras isoladamente se os olhos forem vendados e a letra for manuseada. A dificuldade apresenta-se somente na leitura, que se torna impossível aos olhos. Nessa configuração, a alexia pura é definida como a incapacidade de realizar, contrariamente aos leitores normais, a leitura em paralelo das letras que compõem uma palavra (DEHANE, 2007).

\section{Meios Digitais para a Leitura}

Marshall McLuhan (1962), ao propor que o "meio é a mensagem", quis enfatizar que a estrutura e a organização intrínseca dos canais de informação determinam a maneira como interagem com os processos mentais utilizados na sua decodificação. O surgimento de novas tecnologias de 
comunicação molda a cognição dos indivíduos. A partir da invenção da imprensa, por exemplo, surge a "Galáxia de Gutenberg" (MACLUHAN, 1962), que transforma a antiga dimensão oral do conhecimento, difundida por lendas, histórias e tradições, em uma dimensão visual com o surgimento dos livros impressos. Se, por um lado, esse redimensionamento permitiu a otimização da difusão do conhecimento, por outro, interferiu na tradição oral. O advento das novas tecnologias de informação, aliado aos livros impressos, permite ampliar a capacidade interativa do texto, juntando sons, imagens e outros recursos sensoriais a serviço da leitura.

Um exemplo do potencial estimulador do uso de novas tecnologias é o fenômeno dos videogames, cujo uso vem aumentando ao longo de várias décadas em todas as faixas de idade, mas principalmente entre crianças e adolescentes (LEE et al., 2009). A popularidade dos videogames e as suas potencialidades para desenvolver habilidades perceptuais, cognitivas e motoras (GREEN; BAVELIER, 2003, 2006, 2007; GREEN et al., 2010; LEE et al., 2009) têm motivado um aumento do interesse na sua aplicabilidade no contexto educacional (CONNOLLY et al., 2012). Por exemplo, vários estudos demonstram que o uso de videogames provoca mudanças estruturais em áreas do córtex pré-frontal associadas com memória operacional e outras funções executivas (KÜHN et al., 2014).

Com o advento crescente de computadores com capacidade de processamento cada vez mais sofisticada, abre-se a possibilidade concreta de expandir a maneira como o leitor interage com o texto, incluindo a utilização de tecnologias de realidade virtual e realidade aumentada. Esses desenvolvimentos são essenciais para cativar uma nova geração de leitores, cada vez mais familiarizados com as tecnologias da informação e suas possibilidades, desde o surgimento da cultura dos videogames em décadas anteriores.

A diferença entre a realidade virtual e a aumentada é que a primeira situa o usuário em um ambiente completamente sintético, enquanto a realidade aumentada desempenha um papel suplementar, ao invés de substituir a realidade. Idealmente, os objetos utilizados em sistemas de realidade aumentada devem ser percebidos como coexistindo com o mundo real e podem ser de vários tipos, incluindo texto, animação, videoclipes, sons, etc.

Livros com realidade aumentada (RA) são livros similares a livros físicos, com a diferença de que as páginas de um livro RA possuem conteúdo virtual que pode ser acessado com um dispositivo eletrônico auxiliar (ROBERTO et al., 2013). Embora a tecnologia de livros eletrônicos tenha se desenvolvido e se popularizado bastante nos últimos tempos, a fisicalidade dos livros de papel ainda é um fator importante e deve garantir sua permanência ainda por muito tempo (SELLEN; HARPER, 2003). As tecnologias utilizadas para implementar a RA incorporam o livro físico, adicionando uma camada de tecnologia com apelo importante para as novas gerações. Um livro RA necessita de três elementos: um livro físico, um computador e um dispositivo para apresentar a realidade aumentada (MATCHA; RAMBLI, 2012). Existem várias evidências de que livros RA motivam os estudantes para a leitura (BILLIGHURST; DUENSER, 2012).

\section{Benefícios da Leitura}

Além do papel na transmissão cultural e tecnológica, a leitura também contribui para promover o desenvolvimento cognitivo de maneira mais generalizada (STANOVICH, 1993). A leitura desempenha um papel importante no desenvolvimento da habilidade de inferir o estado mental de outras pessoas, a chamada teoria da mente (TDM), ou mentalização, que é essencial para a convivência em grupos sociais (CASTELLI et al., 2002, PREMACK; WOODRUFF 1978). Mason e Just (2006) propõem que a TDM também está envolvida em rede com outras funções cognitivas importantes, tal como a compreensão de conceitos sociais (MARTIN; WEISBERG, 2003) e a capacidade de fazer julgamentos morais (GREENE et al, 2001; MOLL et al, 2002). Sobre essa base, a TDM adquire um papel central para a compreensão humana. Isso, aliado particularmente ao fato de as crianças serem capazes de atribuir emoções, crenças e motivações a outras pessoas a partir dos quatro anos de idade (ASTINGTON et al., 1988), torna-a importante quando o ensino da leitura é associado ao uso de obras ficcionais.

Vários estudos têm apontado que a TDM é engajada de maneira consistente durante a leitura de ficção (MAR; OATLEY, 2008). Dessa forma, a leitura regular de literatura de ficção pode contribuir para melhorar a cognição social (MAR et al., 2009). Por exemplo, foi demonstrado que a leitura de livros infantis pelos pais está correlacionada com a melhora da competência socioemocional de crianças pré-escolares (MAR et al., 2010). Esses achados são corroborados por estudos de neuroimagem que mostram uma superposição no padrão de ativação cerebral da TDM e a compreensão de narrativas ficcionais (MAR, 2011).

Nossa hipótese, compartilhada com outros autores, como, por exemplo, Oakley (2008), é de que a leitura de ficção requer um engajamento consistente da teoria da mente. Isso pode ser observado em crianças, por exemplo, quando lhes é solicitado que criem um final alternativo para uma história que termina de forma injusta ou incoerente. A forma como irão propor a resolução do dilema pode 
indicar se estão conseguindo simular o que se passa na mente dos personagens da história, configurando-se aí a mentalização (CASTELLI et al., 2002, PREMACK; WOODRUFF 1978), a compreensão de conceitos sociais (MARTIN; WEISBERG, 2003) e a capacidade de fazer julgamentos morais (GREENE et al., 2001; MOLL et al., 2002), numa configuração em rede, tal como apontado por Mason e Just (2006).

A TDM, aliada à leitura de obras de ficção, funciona como um "simulador de voo", permitindo ao leitor criar modelos mentais fictícios e treinar essa capacidade simulatória que ajuda a tomar decisões complexas (OAKLEY, 2008). A leitura de uma narrativa ficcional expande o escopo da perspectiva do leitor quanto a uma determinada experiência e pode mudar suas crenças e comportamentos (KAUFFMAN; LIBBY, 2012). Esse efeito da leitura de ficção pode ser utilizado em intervenções voltadas para reduzir o preconceito e a estereotipagem. Em um estudo recente, por exemplo, foi demonstrado que a leitura de narrativas induz à assimilação de conceitos menos estereotipados e preconceituosos de situações, ampliando e favorecendo a compreensão em determinados grupos (GABRIEL; YOUNG, 2011).

\section{A RA em livros infantis e o desenvolvimento da compreensão leitora}

É importante retomar um aspecto anteriormente apresentado no texto, que responde uma pergunta crucial surgida há pouco mais de uma década como preocupação dos processos de aprendizado da leitura: como o cérebro é capaz de ler? Para ler, é preciso que áreas visuais localizadas no lobo occipital (parte posterior do cérebro) e no lobo temporal (parte inferior do cérebro) sejam adaptadas para reconhecer as letras do alfabeto e essa informação seja transmitida às áreas da linguagem, situadas no lobo temporal e parte inferior do lobo frontal, ambos localizados no hemisfério esquerdo. Dessa forma, a partir do reconhecimento visual das letras (desde que sejam ensinadas e aprendidas), o cérebro converte essa informação visual em som e em significado.

O livro digital que utiliza a realidade aumentada tem o potencial de contribuir para a compreensão leitora de três importantes maneiras (BAJARD, 2002). A primeira é pela relação de difusão e complementaridade que a imagem estabelece com o texto ao oferecer uma solução imediata à incompreensão inicial da escrita pela criança em processo de alfabetização. A segunda é por apresentar um referencial de imagem que possibilita ao leitor iniciante inferir as regras do funcionamento da escrita. Em terceiro lugar, porque sugere respostas às perguntas do leitor que busca o sentido do texto. Em síntese, o livro digital, por meio das suas imagens, pode contribuir para a construção da compreensão do que é a escrita, suas regras de organização e do seu sentido enquanto a criança ainda não domina o sistema de notação da escrita. Ensinar, na perspectiva da escrita como um sistema de notação, supõe partir do princípio de que escrita alfabética não é um código estabelecido dentro de um sistema que simplesmente transpõe graficamente as unidades sonoras mínimas da fala (os fonemas), mas, sim, um sistema de representação escrita (notação) dos múltiplos segmentos sonoros da linguagem falada em uma determinada língua (FERREIRO, 1995; MORAIS, 2005). Para isso é preciso desvendar metalinguisticamente um verdadeiro enigma: como a escrita representa as diferentes notações da pauta sonora. Dessa maneira, justifica-se a importância do largo manuseio, leitura e contação de livros de histórias infantis antes e durante o processo formal de alfabetização.

Como já destacado, insere-se de forma importante para o alcance da compreensão leitora a capacidade de inferir, ler as emoções, intenções e crenças em outras pessoas, apesar da nossa incapacidade de deduzi-las a partir da experiência direta dos estados mentais, a chamada de Teoria da Mente (PREMACK, WOODRUFF, 1978). A TDM é uma habilidade essencial para convivência em grupos sociais (PREMACK, WOODRUFF, 1978; JABBI, SWART, KEYSERS, 2007) e que está emblematicamente ligada à compreensão leitora e ao fato da leitura funcionar como um "simulador de voo" das habilidades sociais, preparando o leitor para sua vivência futura com uma maior experiência e um escopo de decisões mais acertadas sobre as questões emblemáticas vividas. Em função de a leitura de ficção provocar o engajamento do leitor com a trama, nossa hipótese de trabalho é que, por isso, a leitura de ficção provoca um engajamento consistente da teoria da mente (OAKLEY, 2008; MAR, 2009), fazendo com que o leitor passe implicitamente à condição de protagonista se inserindo na mente dos personagens com os quais se identifica ao escutar ou ler a história. O livro digital mais adiante apresentado situa-se nessa perspectiva de dimensionamento.

Outro aspecto importante na utilização de livros com RA na literatura infantil prende-se ao fato de que a cultura e as experiências com imagens fazem parte do nosso processo civilizatório, marcando nossos espaços sociais desde sempre. A escola vai aos poucos atendendo a essas demandas, conforme as tecnologias avançam. Embora o livro físico tenha se convertido numa das mais notáveis tecnologias inventadas pelo homem, na atualidade, novos contextos juntam-se a ele. A escola ainda é iniciante no estudo e trabalho da leitura por meio dos livros de realidade virtual aumentada, mas aos poucos isso passa a ser modificado em nichos de desenvolvimento que possibilitam sua aplicação concreta na cultura escolar. 
Partilhamos a seguir com os leitores algumas páginas de um livro digital ${ }^{1}$ (Figuras 1 e 2) que configura essa situação e que estabelece posição frente à recepção da leitura pela criança, aliada à literatura ficcional e à valorização da imagem como aparato importante na aprendizagem e ampliação da cognição, contemplando a tecnologia como mais um recurso para o contato e aprendizagem da cultura humana escrita e tecnológica. $\mathrm{O}$ livro está inserido nos materiais linguístico-pedagógicos sob a forma de kits (de contação de histórias, atividades de compreensão leitora e atividades fônicas, morfossintáticas, semânticas e pragmáticas), criados para o projeto Leitura + Neurociências: tempo espaço e atividades pedagógicas inovadoras no Programa Mais Educação ${ }^{2}$. A proposta é utilizar o potencial da literatura na formação dos professores e monitores no âmbito do Projeto $\mathrm{L}+\mathrm{N}$, que tem como objetivo desenvolver metodologias inovadoras com vistas a ampliar a competência leitora dos alunos do ensino fundamental. A metodologia utilizada integra a prática da educação com a pesquisa em Educação, Ciência da Computação, Psicolinguística e Neurociências, na configuração de um processo de alfabetização ágil e adequado ao desenvolvimento biopsicossocial infantil da atualidade.

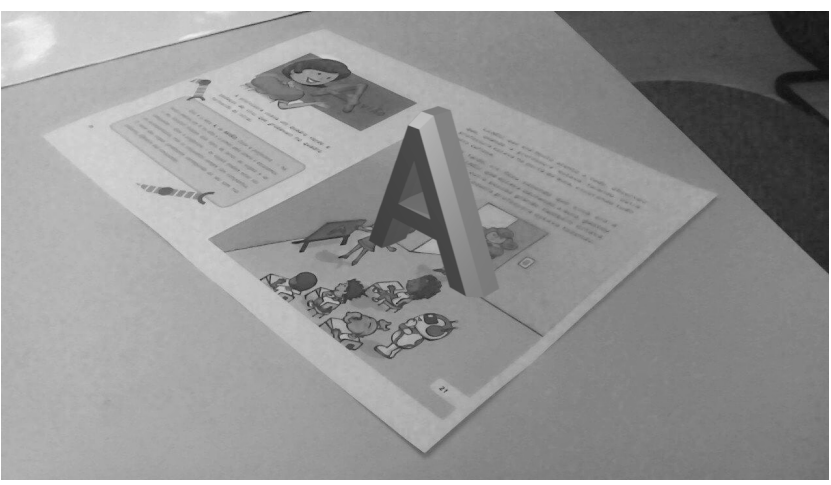

Fig. 1. Página em RA do livro "L.I.Neu e o enigma das letras". (Fonte: Autores)

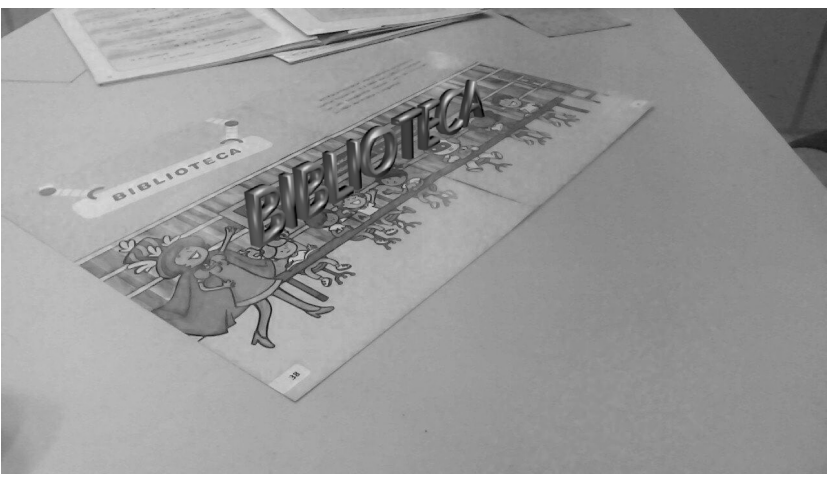

Fig. 2. Página em RA do livro "L.I.Neu" e o enigma das letras. (Fonte: Autores)
O livro conta a história de um robozinho vindo não se sabe de onde que desperta numa caverna escura e, ao sair da escuridão, se maravilha com tudo que enxerga neste nosso planeta azul. E é nesse encantamento que ele entra em uma escola e depara-se com o enigma das letras, junto com a turma entusiasmada de uma professora carismática e competente que está alfabetizando as crianças. Trata-se de um livro para ser lido por um adulto e "contado" para as crianças com o auxílio das ilustrações. A contação de histórias é uma tradição humana milenar que continua encantando as novas gerações de crianças do mundo inteiro.

Durante o processo inicial de aprendizado da leitura, o uso da RA em livros digitais de ficção assume junto ao jovem leitor importante papel de suporte na busca do sentido da narrativa. O contato com a imagem de início é o único contato direto que a criança tem com o livro (ESCARPIT, 1981). Sobre a relação entre narrativa e imagem sempre que num livro infantil o verbal e o não verbal estão harmoniosamente articulados a imagem vai muito além de configuração meramente ilustrativa, pois há dupla narração, a do texto verbal e a do texto não verbal (CAMPOS, 2007). No caso do livro infantil de RA, esses aspectos são ampliados, pois se juntam a ambos (texto e imagem) o movimento e a inovação tecnológica da RA, aspectos esses especialmente adequados à cognição infantil e ao tempo presente. Nessa configuração, abre-se a possibilidade de potencializar de forma harmoniosa e interessante a compreensão leitora ao destacar ao jovem leitor por meio da RA o início, os momentos-chave e ofinal da história, sugerindo uma ideia não dita, expressando ações e emoções, apresentando objetos, cenários, personagens, profundidades e claridades, sons e cores do texto e, por que não, letras, sílabas e palavras, tal como exemplificado nas figuras, entre outros elementos.

Nesse contexto, o livro com RA é concebido para ser disponibilizado aos professores como ferramenta de apoio às atividades de ampliação da compreensão leitora, tornando possível recontar histórias em versão digital de maneira mais dinâmica e interativa com vídeos, animações e/ou livro digital desenvolvido pelas próprias crianças. Esses softwares ou aplicativos foram desenvolvidos com base nos princípios científicos das

\footnotetext{
O livro L.I.NEU e o enigma das letras foi publicado pela Editora da UFRN, com apoio do Programa Mais Educação da Secretaria de Educação Básica do Ministério da Educação.

2 Projeto coordenado por Angela Chuvas Naschold (Curso de Pedagogia/ UFRN) e desenvolvido com a participação dos seguintes professores da UFRN: Antonio Pereira (Instituto do Cérebro), André M. C. Campos, (Curso de Informática e Matemática Aplicada) André L. S. de Pinho (Curso de Estatística), João Alchieri (Curso de Psicologia), Joseli Brazorotto (Curso de Fonoaudiologia), Marly Amarilha (Curso de Pedagogia), Michele Soltosky (Curso de Fonoaudiologia), Selan Rodrigues dos Santos (Curso de Informática e Matemática Aplicada) e Sheila Balen(Curso de Fonoaudiologia).

3 O nome L.I.Neu é a abreviatura de Leitura na Interface com as Neurociências.
} 
áreas de Interação Humano-Computador, Realidade Virtual e Computação Gráfica, dentro da Ciência da Computação. As tecnologias interativas, tais como multimídia, hipermídia e realidade virtual e aumentada, possuem grande potencial para aplicações na área educacional, que vão desde a apresentação de conteúdos multimídia interativos à intermediação entre aluno e professor, ou entre aluno e aluno.

Atualmente, com o surgimento de interfaces inovadoras, é possível desenvolver novas realidades de ensino-aprendizagem baseadas em dispositivos com interfaces touchscreen (de toque) ou com reconhecimento de gestos. Esses dispositivos apontam para uma era de interação mais natural e intuitiva entre homem e máquina, sendo que a tendência é surgirem cada vez mais aparelhos com suporte ao toque e outras formas de interação tal como proposto no livro digital aqui apresentado e que está sendo utilizado no trabalho com crianças em situação de risco social de duas escolas de Natal (RN) e com as escolas da rede de ensino municipal do município de Ipanguaçu (RN), localizado no interior do nordeste brasileiro.

Neste trabalho, com o auxílio da realidade virtual aumentada, abre-se a oportunidade tanto de ensinar a notação da escrita pela organização mais lógica do ensino, considerando a arquitetura cerebral, quanto de propiciar o acesso à compreensão leitora mais elevada. Sob essa perspectiva, as imagens virtuais aumentadas destacam no texto as letras, sílabas e palavras, ao mesmo tempo em que contribuem de forma interessante e inovadora para o alcance da compreensão do sentido por meio da difusão e da complementaridade que a imagem estabelece com o texto; afinal, como refere Aguiar (2011, p. 25) "para que serve um livro sem figuras nem diálogos?, perguntou-se Alice, entediada, pouco antes de decidir seguir o Coelho Branco até o País das Maravilhas". Dois séculos depois (Alice no País das Maravilhas foi originalmente publicada em meados do séc. XIX), a face dos livros é metamorfoseada tal como a de Alice quando disse à Lagarta: “- Eu... eu... nem eu mesma sei, senhora, nesse momento... eu... enfim, sei quem eu era, quando me levantei hoje de manhã, mas acho que já me transformei várias vezes desde então...”. E Alice espertamente completa para a monossilábica Lagarta: “- Bom, não sei. Talvez a senhora ainda não tenha passado por isso - continuou Alice - mas quando tiver de se transformar numa crisálida... pois isso lhe acontecerá algum dia, não é?... e, depois disso, numa borboleta, tenho a impressão de que achará meio esquisito, não?’. É nessa transformação que as imagens saltam das páginas dos livros infantis e pulam como o Coelho Branco, encantando as novas gerações de crianças do mundo inteiro e contribuindo para o desenvolvimento e a ampliação da compreensão leitora de jovens leitores.

\section{Referências}

AGUIAR, Laura. O poder das imagens. Revista Educação, v. 170, n. 9, p. 25-27, 2011.

ALLINGTON, Richard. L. Fluency: The neglected reading goal. The reading teacher, p. 556-561, 1983.

ASTINGTON, Janet Wilde; HARRIS, Paul L.; OLSON, David Richard. Developing Theories of Mind. New York: Cambridge Univ. Press, 1988.

BADDELEY, Alan D.; HITCH, Graham. Working memory. Psychology of learning and motivation, v. 8, p. 47-89, 1974.

BADDELEY, Alan D. Working memory and language: An overview. Journal of Communication Disorders, v. 36, p. 189208, 2003. http://dx.doi.org/10.1016/S0021-9924(03)00019-4

BAJARD, Elie. Caminhos da escrita: espaços de aprendizagem. São Paulo: Cortez, 2002.

BARRESI, John; MOORE, Chris. Intentional relations and social understanding. Behavioral Brain Science, v. 19, p. $107-$ 154, 1996. http://dx.doi.org/10.1017/S0140525X00041790

BILLINGHURST, Mark; DUENSER, Andreas. Augmented Reality in the classroom. Computer, v. 45, n. 7, p. 56-63, 2012. http://dx.doi.org/10.1109/MC.2012.111

BRASIL, Ministério da Educação. Planejando a próxima década conhecendo as 20 metas do Plano Nacional de Educação. Disponível em: <http://pne.mec.gov.br/programasmetas>. Acesso em: 01 set. 2014.

CAIN, K.; OAKHILL, J.; BRYANT, P. (2004). Children's reading comprehension ability: Concurrent prediction by working memory, verbal ability, and component skills. Journal of educational psychology, v. 96, n. 1, p. 31. http://dx.doi. org/10.1037/0022-0663.96.1.31

CAMPOS, Mariana. Literatura infantil no ensino fundamental: análise da recepção de textos imagéticos e escritos por crianças de 4⿳亠丷a série. Programa de Pós-Graduação da UNESP (Mestrado). Marília/SP: 2007.

CARROLL, Lewis. As Aventuras de Alice no País das Maravilhas. São Paulo: Relógio d'Água, 2009.

COOKE, A. E.; HALLERAN, J. G.; O'BRIEN, E. J. What is readily available during reading? A memory-based view. Discourse Processes, v. 26, p. 109-129, 1998. http://dx.doi. org/10.1080/01638539809545041

DEHAENE, Stanislas; COHEN, Laurent. The unique role of the visual word form area in reading. Trends in cognitive sciences, v. 15, n. 6, p. 254-262, 2011. http://dx.doi.org/10.1016/ j.tics.2011.04.003

DEHAENE, Stanislas. LesNeurones de la lecture. Paris: Odile Jacob, 2007.

DÉJERINE, Contribution à l'étude anatomo-pathologique et clinique des différentes variétés de cécité verbale. Mémoires de la Société de Biologie, v. 4, p. 61-90, 1892.

DIUK, Carlos G; SLEZAK, Diego Fernandez; RASKOVSKY, Ivan; SIGMAN, Mariano; CECCHI, Guillermo A. A quantitative philologie of introspection. Frontiers in integrative neuroscience, v. 6, set. 2012.

ESCARPIT, Denise; FLORES, Diana (Trad.). La literatura infantil y juvenil en Europa. México: Fondo de Cultura Económica, 1981. 
FAILLA, Zoara. Leituras dos "retratos": o comportamento leitor do brasileiro. In: FAILLA, Zoara (Org.). Retratos da leitura no Brasil 3. São Paulo: Instituto Pró-Livro, 2012.

FERREIRO, Emília. Passado e presente dos verbos ler e escrever. São Paulo: Cortez, 2005.

GABRIEL, Shira; YOUNG, Adriana F. Becoming a Vampire Without Being Bitten The Narrative Collective-Assimilation Hypothesis. Psychological Science, v. 22, p. 8, p. 990-994, 2011

GREEN, Chawn S.; POUGET, Alexandre; BAVELIER, Daphne. Improved probabilistic inference as a general learning mechanism with action video games. Curr Biol, v. 20, p. 15731579, set. 2010. http://dx.doi.org/10.1016/j.cub.2010.07.040

GREEN, Chawn S.; BAVELIER, Daphne. Action video game modifies visual selective attention. Nature, v. 423, p. 534-537, 2003. http://dx.doi.org/10.1038/nature01647

GREEN, Chawn S.; BAVELIER, Daphne. Enumeration versus multiple object tracking: the case of action video game players. Cognition, v. 101, p. 217-245, 2006. http://dx.doi.org/10.1016/j. cognition.2005.10.004

GREEN, Chawn S; BAVELIER, Daphne. Action-video-game experience alters the spatial resolution of vision. Psychol Sci., v. 18, p. 88-94, 2007. http://dx.doi.org/10.1111/j.14679280.2007.01853.x

GREENE, J. D.; SOMMERVILLE, R. B.; NYSTROM, L. E.; DARLEY, J. M.; COHEN, J. D. An fMRI investigation of emotional engagement in moral judgment. Science, v. 293 , p. 2105-2108, 2001. http://dx.doi.org/10.1126/science.1062872

HIRSCH, Eric Donald. Reading comprehension requires knowledge - of words and the world. American Educator, v. 27, n. 1, p. 10-13, 2003.

HUDSON, Roxanne F.; PULLEN, Paige C.; LANE, Holly B.; TORGESEN, Joseph K. The complex nature of reading fluency: A multidimensional view. Reading \& Writing Quarterly, v. 25, p. 4-32, 2008. http://dx.doi.org/10.1080/10573560802491208

JABBI, Mbemba; SWART, Marte; KEYSERS, Christian. Empathy for positive and negative emotions in the gustatory cortex. Neuroimage, v. 34, n. 4, p. 1744-1753, 2007. http:// dx.doi.org/10.1016/j.neuroimage.2006.10.032

JASPERS, Karl. The Origin and Goal of History. New Haven, CT: Yale University Press, 1953.

KAUFMAN, Geoff F.; LIBBY, Lisa K. Changing beliefs and behavior through experience-taking. Journal of personality and social psychology, v. 103, n. 1, mar. 2012.

KLAUDA, Susan Lutz; GUTHRIE, John T. Relationships of three components of reading fluency to reading comprehension. Journal of Educational Psychology, v. 100, p. 310-321, 2008. http://dx.doi.org/10.1037/0022-0663.100.2.310

KUHN, Melanie R.; SCHWANENFLUGEL, Paula J.; MEISINGER, Elizabeth B. Aligning theory and assessment of reading fluency: Automaticity, prosody, and definitions of fluency. Reading Research Quarterly, v. 45, n. 2, p. 230-251, mar. 2010. http://dx.doi.org/10.1598/RRQ.45.2.4

KÜHN, Simone; LORENZ, Robert; BANASCHEWSKI, Tobias; BARKER, Gareth J.; BÜCHEL, Cristhian; CONROD, Patricia J.; IMAGEN Consortium. Positive association of video game playing with left frontal cortical thickness in adolescents.
PloS one, v. 9, n. 3, p. e91506, 2014. http://dx.doi.org/10.1371/ journal.pone.0091506

LEE, Sook Jung; BARTOLIC, Silvia; VANDEWATER, Elizabeth A. Predicting children's media use in the USA: Differences in cross-sectional and longitudinal analysis. British Journal of Developmental Psychology, v. 27, p. 123-143, mar. 2009. http://dx.doi.org/10.1348/026151008X401336

MASON, Robert A.; JUST, Marcel Adam. Neuroimaging contributions to the understanding of discourse processes. Handbook of Psycholinguistics, v. 799, 2006. http://dx.doi. org/10.1016/B978-012369374-7/50020-1

MAR, Raymond A.; OATLEY, Keith; PETERSON, Jordan B. Exploring the link between reading fiction and empathy: ruling out individual differences and examining outcomes. Communications, v. 34, p. 407-428, 2009.

MAR, Raymond A.; TACKETT, Jennifer L.; MOORE, Chris. Exposure to media and theory-of-mind development in preschoolers. Cognitive Development, v. 25, n. 1, p. 69-78, 2010. http://dx.doi.org/10.1016/j.cogdev.2009.11.002

MAR, Raymond A. The Neural Bases of Social Cognition and Story Comprehension. Annu. Rev. Psychol, v. 62, p. 103-34, 2011. http://dx.doi.org/10.1146/annurev-psych-120709-145406

MARTIN, A.; WEISBERG, J. Neural foundations for understanding social and mechanical concepts. Cognitive Neuropsychology Special Issue: The organization of conceptual knowledge in the brain: Neuropsychological and neuroimaging perspectives, v. 20, p. 575-587, 2003.

MATCHA, Weight Loss; AWANG, Rambli Dayang Rohaya. Design consideration for augmented reality book-based application for collaborative learning environment. In: Computer \& information science international conference. IEEE, 2012. p. 1123-1126.

MCLUHAN, Herbert Marshall. The Gutenberg Galaxy: The Making of Typographic Man. Oxford, UK: Routledge and Kegan Paul, 1962.

MOLL, J.; OLIVEIRA-SOUZA, R. de; BRAMATI, I. E.; GRAFMAN, J. Functional networks in emotional moral and nonmoral social judgments. Neuroimagem, v. 16, p. 696-703, 2002. http://dx.doi.org/10.1006/nimg.2002.1118

MORAIS, Artur Gomes; LEITE, Tania Maria Rios. Como promover o desenvolvimento das habilidades fonológicas dos alfabetizandos? In: MORAIS, Artur Gomes; ALBUQUERQUE, Eliana Borges Corre; LEAL, Telma Ferraz. Alfabetização: apropriação do sistema de escrita alfabética. Belo Horizonte: Autêntica, 2005. p. 71-88.

NATIONAL Reading Panel. Teaching children to read: an evidence-based assessment of the scientific research literature on reading and its implications for reading instruction. Washington, DC: U.S. Government Printing Office, 2000

NASCHOLD, Angela et al. A contribuição das metáforas para a compreensão leitora no contexto da cognição infantil na perspectiva da educação integral. Cognição e linguagem. Natal: EDUFRN, 2015.

NASCHOLD, Angela Chuvas; PEREIRA, Antonio; COSTA, Carolina (Ilustr.). L.I.Neu e o enigma das letras. Natal: EDUFRN, 2014b. 
NEVO, Einat; BREZNITZ, Zvia. Assessment of working memory components at 6years of age as predictors of reading achievements a year later. Journal of experimental child psychology, v. 109, n. 1, p. 73-90, 2011. http://dx.doi.org/ 10.1016/j.jecp.2010.09.010

OATLEY, Keith. The mind's flight simulator. The Psychologist, v. 21, p. 1030-1032, 2008.

OATLEY, Keith; MAR, Raymond A.; DJIKIC, Maja. Effects of reading on knowledge, social abilities, and selfhood. In: ZYNGIER, S. et al. (Ed.). Directions in empirical literary studies: In honor of Willie van Peer. Amsterdam: Benjamins, 2008. p. 127-137. http://dx.doi.org/10.1075/lal.5

OECD. Education at a Glance 2012: OECD Indicators, OECD Publishing, 2012.

ONG, Walter J. Orality and Literacy: The Technologizing of the Word. London, UK: Methuen, 1982. http://dx.doi. org/10.4324/9780203328064

PFLUGSHAUPT, Tobias et al. About the role of visual field defects in pure alexia. Brain, v. 132, p. 1907-1917, abr. 2009. http://dx.doi.org/10.1093/brain/awp141

PREMACK, David G.; WOODRUFF, Guy. Does the chimpanzee have a theory of mind? Behavioral and Brain Sciences, v. 1, p. 515-526, 1978. http://dx.doi.org/10.1017/ S0140525X00076512
ROBERTO, Rafael; FREITAS, Daniel; SIMÕES, Francisco; TEICHRIEB, Veronica. A dynamic blocks platform based on projective augmented reality and tangible interfaces for educational activities. In: Virtual and Augmented Reality (SVR), XV Symposium on. IEEE, 2013. p. 1-9.

SELLEN, Abigail J.; HARPER, Richard HR. The myth of the paperless office. MIT press, 2002.

STANOVICH, Keith E. Does reading make you smarter? Literacy and the development of verbal intelligence. Advances in child development and behavior, v. 24, p. 133-180, 1993. http://dx.doi.org/10.1016/S0065-2407(08)60302-X

WOLF, Maryanne; KATZIR-COHEN, Tami. Reading fluency and its intervention. Scientific studies of reading, v. 5, n. 3, p. 211-239, 2001.

Recebido: 31 de agosto de 2014 Aprovado: 14 de outubro de 2014

Contatos:anaschold@gmail.com sheila@sheilabale.com.br brazorotto@yahoo.com.br msoltosky@yahoo.com.br andre@dimap.ufrn.br selan.rds@gmail.com pereira@neuro.ufrn.br 